\title{
EFFECT OF MATURATION MEDIA WITH HORMONAL SUPPLEMENT ON IN VITRO MATURATION OF BUFFALO OOCYTES WITH DIFFERENT QUALITIES
}

\author{
Sh. A. Gabr \\ Animal Production Department, Faculty of Agriculture, Tanta University
}

\section{SUMMARY}

This study aimed to evaluate the effect of maturation medium (TCM-199 and DMEM) supplemented with FSH or FSH+hCG on in vitro maturation of buffalo oocytes with different qualities. Buffaloes' ovaries were collected from slaughterhouse and oocytes were recovered by aspiration method. Oocytes quality was ranked based on the number of cumulus cell layers into excellent, good, fair and poor oocytes. Oocytes were in vitro matured in TCM-199 or DMEM media containing hormones. Both maturation media were supplemented with FSH $(10 \mu \mathrm{g} / \mathrm{ml})$ or HCG $(10 \mathrm{IU} / \mathrm{ml})$. Cytoplasmic or nuclear maturation was measured.

Results show significant $(P<0.05)$ effect of medium type on cytoplasmic maturation only in fair oocytes. The effect of medium type on nuclear maturation was significant only on fair and poor oocytes, being higher with DMEM than TCM-199 (51.5 vs. 26.8\% and 32.8 vs. 16.1\%). The differences in nuclear maturation of excellent and good oocytes between TCM and DMEM were not significant. Excellent and good oocytes showed higher $(P<0.05)$ maturation rate $(76.7$ and $70.9 \%)$ than fair and poor oocytes (40.2 and 24.6\%), respectively. In general, the highest maturation rate was obtained from excellent oocytes matured by DMEM (81.3\%). The highest percentage of oocytes showing full expansion was for excellent, good and fair by DMEM supplemented with FSH (79.3, 67.6 and 50\%, respectively. These findings may suggest the beneficial effects of hormonal addition on cumulus cells expansion for all oocyte qualities, except poor oocytes. Maturation rate was the highest $(P<0.05)$ for excellent, good and fair oocytes matured by DMEM supplemented with FSH plus hCG. However, the poor oocytes showed the highest $(P<0.05)$ maturation rate with DMEM supplemented with FSH alone.

Maturation medium (DMEM) supplemented with FSH plus hCG showed the highest in vitro nuclear maturation of buffalo oocytes with different qualities, in particular excellent, good and fair oocytes. Further studies are needed for evaluation the effect of hormonal addition with FSH and/or hCG to DMEM medium on in vitro fertilization and embryo development of buffalo oocytes.

\section{Keywords: Type of Maturation Media- Hormonal supplement- In Vitro Maturation- Buffalo Oocytes}

\section{INTRODUCTION}

In Egypt, buffaloes are considered as the main dairy animals and known to suffer from many reproductive problems (El-Moghazy, 2003). Early efforts have been initiated to augment the reproductive potential of these animals using biotechnology (Madan et al., 1994). In vitro fertilization (IVF) technology provides an opportunity to produce embryos for genetic manipulation and embryo transfer (Nandi et al., 2002). Producing embryos by IVF is based on three subsequent techniques: oocyte in vitro maturation (IVM), IVF and in vitro culture (IVC) for cleavage up to blastocyst stage (Goswami et al., 2004).

Oocyte maturation is the foundation of embryo production (Abdoon, 2002). Oocyte maturation is the most critical step towards successful in vitro embryo production. The culture medium and selection of protein supplements and hormones for IVM play an important role in the subsequent maturation rate, and embryonic development following IVF (Bavister et al., 1992). Several factors such as addition of FSH, LH and their combination to culture media had been considered for maximizing success (Saeki et al., 1990). Little information is available on in vitro maturation and fertilization of buffalo oocytes (Shamiah, 2004), which is relatively poor when compared to cattle as reported by Bacci et al. (1991) and Totey et al. (1992).

The present work aimed at evaluating the effect of type of maturation media (TCM-199 and DMEM) with hormonal addition (FSH or FSH + hCG) on in vitro maturation of buffalo oocytes with particular reference to qualities.

\section{MATERIALS AND METHODS}

The present study was carried out in the Department of Animal Production, Faculty of Agriculture, Tanta University and Department of Animal Reproduction and Artificial Insemination, Veterinary Research Division, National Research Center, during the period from January 2010 to May 2011.

All chemicals and media used in this study were purchased from Sigma-Aldrich (Sant. Louis, MO, USA) unless otherwise mentioned. 
Ovaries collection:

Ovaries were collected within 20-30 min post-slaughtering of buffalo cows from ElMoneib slaughterhouse, Giza City and transported to the laboratory within two to three $\mathrm{h}$ in an insulated thermos containing normal sterile saline solution (NSS, $0.9 \%$ $\mathrm{NaCl}$ ) supplemented with $100 \mathrm{I} . \mathrm{U} / \mathrm{ml}$ penicillin and $100 \mu \mathrm{g} / \mathrm{ml}$ streptomycin.. Upon arrival, ovaries were washed onetime with ethayl alcohol to minimize the risk of contamination followed by several times with warm NSS at $37^{\circ} \mathrm{C}$ until obtaining clear saline free from blood and then kept in water bath at $37^{\circ} \mathrm{C}$ for oocyte collection.

\section{Oocyte recovery:}

HEPES buffered tissue culture medium (HTCM-199, catalogue number M-2520) supplemented with four $\mathrm{mg} / \mathrm{ml}$ bovine serum albumin (BSA) and $50 \mu \mathrm{g} / \mathrm{ml}$ Gentamycin was used as aspiration medium. Oocytes were recovered by aspiration method using 18gauge needle attached to $10 \mathrm{ml}$ disposable syringe containing one $\mathrm{ml}$ aspiration medium. The contents of the syringe were placed into 15 $\mathrm{ml}$ sterile falcon tube (Falcon, USA) and kept in water bath at $37^{\circ} \mathrm{C}$ for $15 \mathrm{~min}$, to allow oocytes to settle down. After settling the sediment at the bottom of the Falcon tube was aspirated using Pasture pipette and placed into in six $\mathrm{cm}$ diameter polysterene sterile Petri dish containing five $\mathrm{ml}$ aspiration medium for searching oocytes under stereo-microscope.

Assessment of oocytes quality was determined depending upon the number of cumulus cell layers surrounding the oocyte and the homogeneity of ooplasm under stereomicroscope (Nakamura, Japan) at x 32 according to Furnus et al. (1997) into excellent, those surrounded by compact and cumulus cell layers ( $\geq$ four layers) and homogenous evenly granular ooplasm; good, those surrounded by two to three layers of cumulus cells and homogenous evenly granular ooplasm; fair, those surrounded by one layer of cumulus cells, and poor (Denuded) those were completely devoid of cumulus cells around them and uneven ooplasm.

\section{In vitro maturation:}

Oocytes were washed two times by HEPES buffer TCM-199 (TCM199, Cat. 2415) or DEMM (Dulbecco's modified eagle medium) containing $10 \mathrm{IU} / \mathrm{ml} \mathrm{FSH}$, four \% BSA and 50 $\mu \mathrm{g} / \mathrm{ml}$ Gentamycin, then washed again by maturation medium ( $\mathrm{pH} 7.2-7.4)$ and finally each class of oocytes was cultured in a separate well of a four-well culture plate (Nunclon, Denmark) containing maturation medium for $24 \mathrm{~h}$ at $38^{\circ} \mathrm{C}$ under $5 \% \mathrm{CO}_{2}$ in $\mathrm{CO}_{2}$ incubator. All media used in the present work were filtered using $0.2 \mu \mathrm{m}$ (Millipore, USA) syringe filter and incubated for at least two $\mathrm{h}$ in a humidified atmosphere $(95 \%)$ under $5 \% \mathrm{CO}_{2}$ at $38^{\circ} \mathrm{C}$ before culturing of the oocytes

To study the effect of hormonal addition to both maturation media, FSH $(10 \mu \mathrm{g} / \mathrm{ml}) v s$. TCM $199+$ FSH $(10 \mu \mathrm{g} / \mathrm{ml})$ and HCG (10 $\mathrm{IU} / \mathrm{ml})$ were added to TCM-199 or DMEM media. Both types of maturation media were supplemented also with $10 \%$ FCS and $50 \mu \mathrm{g} /$ $\mathrm{ml}$ Gentamycin.

Cytoplasmic maturation was measured by assessing the degree of cumulus-cells expansion as described by Abd El-Kader (2005) under stereomicroscope. Oocytes without expansion (Grade 0, Go), few expansions of cumulus layers (Grade 1, G1), moderate expansions of cumulus layers (Grade 2, G2) and full expansion of cumulus layers (Grade 3, G3) were determined. Oocytes were removed from the maturation medium and the cumulus- cells were removed by gentile repeated pipetting using $100 \mu \mathrm{l}$ pipette and then fixed in acetic acid and ethanol (1:3) (Totey et al., 1993) for minimum $48 \mathrm{~h}$ for detection of nuclear maturation.

Two to three fixed oocytes in a drop were aspirated by an automatic pipette and placed on glass slide. A cover slip, with inert paraffin wax spots at each of its four corners, was placed directly over the center of the drop containing the oocytes. Thereafter, the oocytes were observed under stereomicroscope, the cover slip was pressed down on the oocytes until it was held firmly in place. The slide was stained with aceto orcein stain (one gm orcein+ $45 \mathrm{ml}$ glacial acetic acid + $55 \mathrm{ml}$ DDW) for five min and washed by aceto-glycerol (3:1).

Nuclear maturation of oocytes was carried out according to Sirard et al. (1989) into Germinal vesicle (GV), interphase chromosomes enclosed within a nuclear membrane; Germinal vesicle breakdown (GVBD), an absence of a visible nuclear membrane and the chromatin condensation was characterized by a cluster of DNA material without individual chromosomes; Anaphase I (A I), separation of homologous pairs of chromosomes and the chromosomes were pulling apart from each other and moving to the opposite poles of the spindle; Telophase 1 (T I), the two groups of equally spread homologous chromosomes reached the opposite poles of the spindle; Metaphase II, separation of homologous chromosomes with extrusion of first polar body, and Degenerated oocytes, being vacuolated or having scattered or highly condensed chromatin.

Oocytes were classified as immature oocytes, at either germinal vesicle stage $(\mathrm{GV})$ or germinal vesicles break down stage (GVBD); mature oocytes, anaphase (An), 
Telophase (T) and Metaphase II (M II with polar body) stages and unidentified or degenerated oocytes (Abd El-Kader, 2005).

Statistical analysis:

Data were statistically analyzed using Chisquare.

\section{RESULTS AND DISCUSSION}

Effect of type of maturation medium on IVM: Cytoplasmic maturation with TCM-199 vs. DMEM

Effect of medium type on cytoplasmic maturation was observed only on fair oocytes. However, the differences in cumulus cells expansion among excellent and good oocytes were not significant with TCM or DMEM. Yet poor oocytes failed to show full expansion with both media. Percentage of fair oocytes with full cumulus cells expansion was higher $(\mathrm{P}<0.05)$ with DMEM than TCM (Table 1$)$.

The culture medium is one of the most important factors in maturation of follicular oocytes in vitro (Van De Sandt et al., 1990 and Palta and Chauhan, 1998) and expansion of cumulus cells depends largely on the culture media used for maturation of the oocytes (Nandi et al., 2002). TCM-199 is capable of supporting the in vitro maturation of bovine (Lonergan et al., 1994) and buffalo (Hammam et al., 1997) oocytes.

In the present study, DMEM medium showed better effect on expansion of cumulus cells than TCM-199 on IVM of fair oocytes. In the same concern, Gliedt et al. (1996) found that cumulus cells expansion was greater $(\mathrm{P}<0.0001)$ for bovine COC that matured in RPMI-1640 than for those that matured in TCM-199. Several authors found that cumulus cells expansion of buffalo oocytes was $(\mathrm{P}<0.01)$ for MSOF than TCM-199 medium (Ali, 2004; Barakat, 2005 and Abdel-Razik, 2007).

Comparing oocyte quality regardless type of medium, excellent oocytes showed the best $(\mathrm{P}<0.05)$ cytoplasmic maturation $(55.1 \%)$ as compared to good (43.8\%) or fair $(20.6 \%)$ oocytes. It is of interest to note that the highest percentages of oocytes with full cumulus cell expansion (G3) in relation to medium type and oocyte quality was obtained with excellent buffalo oocytes matured by TCM-199 (56.5\%), which was associated with revisable percentages of oocytes without expansion (G0, Table 1).

In accordance with the present results, Abdel-Razik (2007) found that the percentage of buffalo oocytes that reached full expansion was $67.4 \%, 57.4,47.2$ and $0.0 \%$ for excellent, good, fair and poor quality oocytes, respectively. Also, Barakat (2005) reported that oocyte quality affected cumulus expansion, where the excellent and good oocytes gave higher cumulus expansion than other grades. In this respect, a positive correlation between viability of hamster cumulus cells and ability to undergo expansion during maturation (Leibfried-Ruttledge et al., 1986) and between numbers of excellent and good quality oocytes and number of oocytes that showed full expansion (Abd El-Kader, 2005).

The recorded highest rate of cumulus cells expansion of the excellent oocytes was attributed to the number of layers of cumulus cells surrounding the oocytes. Good and fair quality oocytes had less number of cumulus cell layers and less percentage of cumulus cells expansion (Abdel-Razik, 2007). The existence of a healthy population of somatic cells surrounding the oocyte is mandatory to facilitate the transport of nutrient and signals into and out of the oocyte (Osborn and Moor, 1982). The role of cumulus cells in providing nutrients to the oocyte during its growth, to participate in the zona formation and following the LH surge to synthesize the matrix composed of proteins and hyaluronic acid was reported by Bedford and Kim (1993). The observed higher cumulus expansion may be due to the participation of oocytes for cumulus cells to synthesize hyaluronic acid and undergo cumulus expansion in vitro (Buccino et al., 1990).

\section{Nuclear maturation with TCM-199 and DMEM:}

Table (2) shows that the effect of medium type on nuclear maturation was significant only in fair and poor oocytes, being higher with DMEM than TCM-199 (51.5 vs. 26.8\% and $32.8 v s .16 .1 \%)$. The differences in nuclear maturation of excellent and good oocytes between TCM and DMEM were not significant.

In comparable with the present results, maturation rate of bovine oocytes with different qualities was $45.3 \%$ (Smetanina et al., 2000), 62.7\% (Oyamada et al., 2003), $78.2 \%$ (Luo et al., 2002) for DMEM versus 29.4 (Smetanina et al., 2000) and $76.8 \%$ (Abdel-Razik, 2007) for buffalo oocytes matured by TCM-199. In comparison TCM199 with other media, Ali (2004) reported that the maturation percentage of buffalo oocytes using mSOF was $(87.6 \%)$ and lower than that obtained by using TCM-199 medium with growth factors or hormones (93.9 - 96.1\%). Similar results were reported by Barakat (2005) where TCM-199 medium exhibited higher maturation rate $(77.6 \%)$ than $\mathrm{mSOF}$ medium (40.9\%). Also, Raza et al. (2001) revealed that TCM-199 resulted in significant better maturation rate $(73.3 \%)$ than Ham's 10 
(61.6\%). Similar results were obtained by Abdel-Razik (2007), who found that TCM-199 showed higher $(\mathrm{P}<0.01)$ maturation rate of buffalo oocytes than that of mSOF medium (76.8 vs. $71.1 \%$ ).

The difference in maturation percentage among different types of medium may be attributed to the composition of the media (Nandi et al., 2002). TCM-199 contains both glutamine and glucose (Michele et al. 2003). Presence of glucose is essential to generate ATP via glycolytic metabolism, while glutamine can feed into tricarboxylic acid cycle and serves as a potential energy source (Downs and Verhoeven, 2003). The absence of glucose or pyruvate fails to support the spontaneous meiotic maturation of mouse oocytes and does little more than help to maintain oocyte viability (Downs and Hudson, 2000). As affected by oocyte quality, excellent and good oocytes showed higher $(\mathrm{P}<0.05)$ maturation rate $(76.7$ and $70.9 \%)$ than fair and poor oocytes (40.2 and $24.6 \%$ ), respectively. However, the differences between fair and poor oocytes were significant. In general, the highest maturation rate was obtained from excellent oocytes matured by DMEM (81.3\%).

It is of interest to observe that poor oocytes did not reach full expansion showed low rate of neaclear maturation with both media, being higher for poor oocytes matured by DMED $(32.8 \%)$ than fair oocytes matured by TCM (29.8\%), reflecting the impact of DMEM on in vitro maturation of low quality oocytes (Table 2).

Resullts obtained in this study are similar to those reported by Leibfried-Ruttledge and First (1979) and Abdel-Razik (2007) for IVM of different oocyte qualities. Also, several authors found that there were marked differences in the rate of maturation of oocytes belonging to various morphological categories (Chain et al., 1995; Chauhan et al., 1998 and Abdoon et al., 2001). These differences indicate the substantial role of cumulus cells in oocyte maturity. In buffaloes, oocytes with homogenous cytoplasm and surrounded compact layers of cumulus cells showed significantly higher maturation rate than those with partial remnants or no cumulus cells (Warriach and Chohan, 2004).

Also, oocytes with expanded, clumbed cumulus cells complex and irregular cytoplasm showed lower rate of in vitro maturation (De Loose et al., 1989). On the other hand, Kim et al. (1997) reported no difference in developmental competence, even though the numbers of cumulus cell layers was low.

In general, cumulus cells are responsible for proper cytoplasmic maturation of the oocyte (Staigmiller and Moor, 1984 and Mori et al., 2000). Ravindranatha et al. (2002) revealed that oocyte maturation was mediated by the cumulus oophori and corona radiate surrounding the oocytes either cumulus expansion or nuclear maturation. Removal of cumulus mass adversely affected the developmental competence of oocytes (Nandi et al., 1998). Also, physical contact between oocyte and cumulus cells is necessary for the transfer of nutrients and other factors essential for oocyte development (Albertini et al., 2001). Cumulus cells keep the oocyte under meiotic arrest (Eppig, 1991) and participate in induction of meiosis (Mattioli and Barboni, 2000). Downs and Verhoeven (2003) concluded that cumulus cells enclosing the oocyte are responsible for the recognition and utilization of oocyte to the added compounds such as glucose and glutamine.

\section{Effect of hormonal addition on IVM: Cytoplasmic maturation:}

Table (3) shows significant effect of hormonal addition to TCM-199 and DMEM on cumulus cells expansion of buffalo oocytes with different qualities. The highest percentage of oocytes showing full expansion was significantly $(\mathrm{P}<0.05)$ obtained when buffalo oocytes with different qualities (excellent, good and fair) were matured by DMEM supplemented with FSH. These findings may suggest the beneficial effects of hormonal addition on cumulus cells expansion for all oocyte qualities, except poor oocytes.

It is of interest to note that addition of FSH to TCM-199 yielded lower full expansion than that of FSH plus hCG addition, especially for excellent and good oocytes. Similarly, AbdelRazik (2007) reported that the in vitro maturation rate of buffalo oocyte was lower with adding FSH than with FSH plus hCG to TCM-199 and mSOF media. Several authors reported that adding gonadotropins (LH, FSH or their analogues, singly or in combination) in maturation media usually had beneficial effects on oocyte maturation (Ravindranatha et al., 2002, Chohan and Hunter, 2003; Ali, 2004 and Abd El- Kader, 2005).

The expansion of cumulus cells depends largely on the culture media used for maturation of the oocytes and supplementation of gonadotrophins in this media. In this respect, Nandi et al. (2002) found that the addition of gonadotrophins alone or with steroids caused significant increase in cumulus expansion.

In accordance with the obtained results for FSH addition to in vitro maturation medium on cumulus cells expansion, many authors suggested that FSH has beneficial effect on expansion of the cumulus cells surrounding the oocyte, which in terms enhance sperm capacitation and the fertilization process 
(Eyestone and Boer, 1993 and Ravindranatha et al., 2002).

Expansion of cumulus cells surrounding bovine oocytes was altered in response to FSH and/or LH in semi-defined medium (Choi et al., 2001). It was explained that both FSH and hCG (mainly LH contaminated with FSH) increased the use of cAMP system as an intracellular second messenger (Bevers et al., 1997) and thus increases the level of activity of hyaluronic acid synthesis enzyme system and induced cumulus expansion in intact complexes (Buccino et al., 1990).

It was observed a direct role of FSH in bovine cumulus expansion which has been supported by the demonstration of receptor for FSH (Bao et al., 1997 and Kito and Bavister 1997). RT-PCR and in situ hyperidization experiments revealed that mRNA for FSH receptor was present in bovine cumulus cells but only few or no LH receptors. Thus, FSH is more effective in cumulus expansion at low concentration than LH (Elvin et al., 1999 and Choi et al., 2001).

On the other hand, Nandi et al. (2002) observed that cumulus cells were stimulated by gonadotropins (FSH and $\mathrm{LH}$ ) to produce and secrete hyaluronic acid (Chen et al., 1990), causing dispersion of cells in a process called expansion and mucification. The presence of gonadotropin hormones in IVM media acts cooperatively to stimulate hyaluronic acid synthesis and maximal expansion of cumulus matrix (Chen et al., 1994).

\section{Nuclear maturation:}

Results presented in Table (4) show that hormonal addition to TCM-199 or DMEM also significantly affected IVM of buffalo oocytes. Maturation rate was significantly $(\mathrm{P}<0.05)$ the highest for excellent, good and fair oocytes matured by DMEM supplemented with FSH plus hCG. However, the poor oocytes showed the highest maturation rate $(\mathrm{P}<0.05)$ with DMEM supplemented with FSH alone.

Such trend may suggest that maturation rate as affected by hormonal addition was also in relation to oocyte quality, being the highest for the excellent oocytes matured by DMEM supplemented with FSH plus hCG and poor oocytes matured by DMEM supplemented with FSH alone. These results indicated that hormonal addition of FSH or FSH plus hCG to TCM-199 had no pronounced effect on in vitro maturation of buffalo oocytes with different qualities as compared to TCM-199. In accordance with the present results, Lawrence et al. (1980) reported that gonadotrophins act on cumulus cells by improving oocyte maturation in vitro. The prominent role of gonadotropins is the stimulation of nuclear maturation of oocytes (Totey et al., 1993). In this respect, Eppig (1991) reported that gonadotrophins, added in vitro to maturation media, enhanced bovine oocyte quality as shown by improved completion of nuclear maturation (95-100\% matured oocytes), fertilization, and developmental ability. The role of gonadotropins in the maturation of oocyte has been widely acknowledged, and the experimental evidence of the resumption of meiosis has been reported when gonadotropins were added to the medium (Sanbuissho and Threfall, 1990; Olson et al., 1991 and Choi et al., 2001).

Plancha and Albertini (1994) suggested that contractile events associated with cytokinesis and polar body extrusion might be under hormonal influence. In this way, Bevers et al. (1997) revealed that both FSH and LH use cAMP system as an intracellular second messenger. The improving IVM of buffalo oocytes by FSH plus hCG may be attributed to that gonadotropins may stimulate cumulus cells of oocyte-cumulus complexes (COCs) to secrete a positive factor that could override arrest due to hypoxanthine and could trigger meiotic resumption (Choi et al., 2001). They also added that LH increased glycolysis and glucose oxidation in oocyte-cumulus complexes and glutamine oxidation in mature oocytes denuded after LH exposure.

Moreover, Zuelke and Brackett (1992 and 1993) demonstrated that one possible mechanism of gonadotropins enhanced oocyte maturation in vitro was to initiate changes in metabolism of COCs. Downs (1993) reported that gonadotrophins stimulate meiotic induction and led to generation of positive factor that acts on oocytes to override the inhibitory influence and to induce germinal vesicle breakdown (GVBD). The observed trend of differences in hormonal addition for TCM-199 or DMEM suggested that hormonal addition to in vitro maturation medium had different effect on both cytoplasmic and nuclear maturation. However, the slight differences in nuclear maturation may reflect the effect of FSH on nuclear maturation of oocyte and that was dependent on substrates present in IVM medium (Ali and Sirard, 2002).

\section{CONCLUSION}

Success in vitro maturation of buffalo oocytes is related to its qualities. Moreover, adding gonadotropins (FSH or FSH plus hCG) to maturation media improved cytoplasm and nuclear maturation. Further studies are needed for evaluation the effect of hormonal addition with FSH and/or hCG to DMEM medium on in vitro fertilization and embryo development of buffalo oocytes. 


\section{REFERENCES}

Abd El-Kader, H.M., 2005.In vitro maturation, fertilization and culture to blastocyst of buffalo oocytes in different culture media. Ph. D Thesis, Faculty of Science, Cairo University, Giza, Egypt.

Abd El-Razik, H.M., 2007.Factors affecting developmental competence of buffalo oocytes. M. Sc. Thesis, Faculty of Vet. Med., Suez Canal University, Egypt.

Abdoon, A.S.S., 2002.Factors affecting in vitro production of bovine embryos. Egyptian Soc. Anim. Reprod. Fert. 14 th Annual congr. In cooperation with Egyption Vet. Nutr. Assoc. Giza 2-7 February.

Abdoon, A.S.S., M.K.T Omaima, T. Otoi and T. Suzuki, 2001.Influence of oocyte quality, culture media and gonadotropins on cleavage rate and development of in vitro fertilized buffalo embryos. J. Anim. Reprod. Sci.; 63: 215-223.

Albertini, D. F., C.M. Combelles, E. Benecchi and M.J. Carabatsos, 2001.Cellular bases for paracrine regulation of ovarian follicle development. Reprod., 121: 647- 653.

Ali, M. S. F. ,2004.Production of Egyptian buffalo embryos using in vitro fertilization technique. M. Sc thesis, Faculty of Agriculture, Cairo University, Giza, Egypt.

Ali, A. and M.A. Sirard, 2002.Effect of the absence or presence of various protein supplements on further development of bovine oocytes during in vitro maturation. Biol. Reprod., 66 (4): 901- 905.

Bacci, M.L., G. Galeat, M. Mattoili, R. Boni and E. Seren, 1991.In vitro maturation and in vitro fertilization of buffalo oocytes. Proc., Third World Buffalo Congress, Varna, Bulgaria. Vol. 3: 599- 603.

Bao, B., H.A. Garyerick, G.W. Smith, M.E. Smith, B.E. Salfen and R.S. Oungquist, 1997.Changes in messenger ribonucleic acid encoding luteinizing hormone receptor, cytochrome $\mathrm{P} 450$ side chain cleavage, and aromatase are associated with recruitment and selection of bovine ovarian follicles. Boil. Reprod., 56:11581168.

Barakat, I.A.H., 2005. In vitro maturation and ultra structural study of Egyptian buffalo (Bubalus Bubalis) oocytes. Ph. D thesis, Faculty of Agriculture. Cairo University, Giza, Egypt.

Bavister, B.D., T.A. Rose-Hellokant and T. Pinnyomminter, 1992.Development of in vitro matured in vitro fertilized bovine embryos into morula and blastocyst in defined culture media. Theriogenology, 37: 127- 146.
Bedford, J.M. and H.H. Kim, 1993.Cumulus oophorus as a sperm-sequestering device in vivo. J. Exp. Zoo., 265: 321- 328.

Bevers, M.M., S.J. Dielman, R. Van der Hunk and F. Izadyar, 1997.Regulation and maturation of oocyte maturation in the bovine. Theriogenology, 47: 13- 22.

Buccino, R., A.C. Schroeder and J.J. Eppig, 1990.Interactions between somatic cells and germ cells throughout mammalian oogenesis. Boil. Reprod., 43: 543.

Chain, R.C., K. Okuda and K. Niwa, 1995.Influence of cumulus cells on in vitro fertilization of bovine oocytes derived from in vitro maturation. J. Anim. Reprod. Sci., 38: 37- 48.

Chauhan, M.S., S.K. Singla, P. Palta, R.S. Manik and M.L. Madan, 1998.In vitro maturation and fertilization, and subsequent development of buffalo (Bubalus bubalis) embryos: effect of oocyte quality and type of serum. J. Reprod. Fertile. Dev., 10 (2): 173-177.

Chen, L., P.T. Russel and W.J. Larsen, 1994. Sequential effects of follicle stimulating hormone and luteinizing hormone on mouse cumulus expansion in vitro. Biol. Reprod., 51: 290- 295.

Chen, L., S.E. Wert, E.M. Hendrix, P.T. Russel, M. Cannon and W.J. Larsen, 1990. Hyaluronic acid synthesis and gap junction endocytosis a necessary for normal expansion of the cumulus mass. Mol. Reprod. Dev., 26: 236- 247.

Chohan, K.R. and A.G. Hunter, 2003.In vitro maturation and fertilization of water buffalo oocytes. Buffalo J., 1: 91- 101.

Choi, Y.H., E.M. Carnevale, G.E. Seidel and E.L. Squires, 2000. Effects of gonadotropins on bovine oocytes matured in TCM-199. Theriogenology, 56:661- 670.

De Loose, F., C. Van Vliet, P. Van Maurik and T.A.M.Kruip, 1989.Morphology of immature bovine oocytes. Gamete Res., 24: 197- 204.

Downs, S.M. and A. Verhoeven, 2003. Glutamine and the maintenance of meiotic arrest in mouse oocytes: influence of culture medium, glucose, and cumulus cells. Mol. Reprod. Dev., 66: 90- 97.

Downs, S.M. and E.D. Hudson, 2000.Energy substrates and the completion of spontaneous meiotic maturation Zygote, 8: 339- 351.

Downs, S.M., 1993.Factors affecting the resumption of meiotic maturation in mammalian oocytes. Theriogenology, 39: 65- 79

Elvin, J.A., A.T.Clark, P.Wang, N.M. Wolfman and M.M.Matzuk, 1999. Paracrine actions of growth differentiation 
factor-9 in the mammalian ovary. Mol. Endocrinol., 13: 1035- 1048.

El-Moghazy, M.M.M.,2003. Physiological studied on the postpartum reproductive performance in buffaloes. Ph. D. Thesis, Fac. Agric., Mansoura Univ., Egypt.

Eppig, J.J., 1991. Mammalian oocyte development in vivo and in vitro, In: wassarman. PM (ed). Elements of mammalian fertilization. Volum I. basic concepts. Bocaraton. FL: CRC. Press:5776.

Eyestone, W.H. and H.A.D. Boer, 1993. FSH enhances developmental potential of bovine oocytes matured in chemically defined medium. Theriogenology, 39: 216.

Furnus, C.C., D.G. De matos, A.G. Martinez and M. Matkovic, 1997.Effect of glucose on embryo quality and post thaw viability of in vitro produced bovine embryos. Theriogenology, 47: 481-490.

Gliedt, D.W., C.F. Rosenkrans, J.R.W. Rorie, A.L. Rorie, J.N. Munyon, J. N., Pierson, G.F. Miller and J.M. Rakes, 1996. Effect of media, serum, oviductal cells, and hormones during maturation on bovine embryo development in vitro. Dairy Sci., 79: 536- 542.

Goswami, P.C., S.Z. Ali, M.A.M.Y. Khandoker, S.A. Azmal, M.K. Alam and R. Khatum, 2004. Collection and grading of bovine cumulus oocyte- complexes (COCs) from slaughter house ovaries in view of in vitro maturation, fertilization and culture. Pakistan J. Biol. Sci., 7: 1777- 1781.

Hammam, A.M., M.M. Zabal and H.A. Sabra, 1997.Effect of type of media on in vitro maturation. Culture and fertilization of buffalo and cattle oocytes. Beni- Swef Vet. Med. Res., 2: 242- 259.

Kim, K.S., N. Minami, M. Yamada and K. Utsumi, 1997.Follicular cells affect the fertilizability and development of bovine oocytes in vitro. J. Reprod. Fertil. Dev., 9 (8): 763- 766.

Kito, S. and B.S. Bavister,1997. Gonadotropins, serum and amino acids alter nuclear maturation, cumulus expansion and oocyte morphology in hamster cumulus oocyte complexes in vitro. Biol. Reprod., 56: 1281- 1289.

Lawrence, T.S., N. Dekel and W.H. Beer, 1980.Binding of human chorionic gonadotropin by rat cumulus oophori and granulosa cells: comparative study. Endocrinol., 106: 1114- 1118.

Leibfried-Ruttledge, M.L., E.S. Critser and N.L. First, 1986. Effects of fetal calf serum and bovine serum albumin on in vitro maturation and fertilization of bovine and hamster cumulus oocyte complexes. Biol. Reprod., 36: 376- 383.
Leibfried-Ruttledge, M.L. and N.L. First, 1979. Characterization of bovine follicular oocytes and their ability to mature in vitro. J. Anim. Sci., 48: 76- 76.

Lonergan, P., P. Monaghen, D. Rizos, M.P. Boland and I. Gordon, 1994.Effect of follicle size on bovine oocyte quality and developmental competence following maturation, fertilization and culture in vitro. Mol. Reprod. Dev., 37: 48- 53.

Luo, H., K. Kimura, M. Aoki, M. Hirako and H.L. Luo, 2002.Effect of vascular endothelial growth factor on maturation, fertilization and developmental competence of bovine oocytes. J. Vet. Med. Sci., 64: 803- 806.

Madan, M.L., S.K. Singla, M. Chauhan and R.S. Manik, 1994. In vitro production and transfer of embryos in buffaloes. Theriogenology, 41: 139- 143.

Mattioli, M. and B. Barboni, 2000.Signal transduction mechanism for $\mathrm{LH}$ in the cumulus-oocyte complex. Mol. Cell. Endocrinol. 161: 19- 23.

Michele, D.C., N.C. Anita, C.S. Lawerence and J.W. Andrew, 2003. Responsiveness of bovine cumulus oocyte complexes to porcine and recombinant human $\mathrm{FSH}$ and the effect of COC quality on gonadotropin receptor and CX43 marker gene mRNAs during maturation in vitro. Reproductive Biology and Endocrinol., 1:14.

Mori, T., T. Amani and H. Shimizu, 2000. Roles of gap junctional communication of cumulus cells in cytoplasmic maturation of porcine oocytes cultured in vitro. Biol. Reprod., 62: 913-919.

Nandi, S., B.M. Ravindranatha, P.S.P. Gupta and P.V. Sarma, 2002. Timing in sequential changes in cumulus cells and first polar body extrusion during in vitro maturation of buffalo oocytes. Theriogenology, 57: 1151- 1159.

Nandi, S., M.S. Chauhan and P. Palta, 1998. Influence of cumulus cells and sperm cell concentration on cleavage rate and subsequent embryonic development of buffalo (Bubalus bubalis) oocytes matured and fertilized in vitro. Theriogenology, 50: 1251- 1262.

Olson, S.E., W.K. Thomas and G.E. Seidel, 1991.Effects of gonadotropins during in vitro maturation of bovine oocytes on subsequent embryonic development. Theriogenology, 35 (1): 250.

Osborn, J.C. and R.M. Moor, 1982.Cell interactions and actine synthesis in mammalian oocytes. J. Exp. Zool., 220: 125- 129.

Oyamada, T., H. Iwayama and Y. Fukui, 2003. Bovine blastocyst production by an individual oocyte culture during 
IVM/IVF/IVC using a chemically defined medium. Therigenology, 22: 348.(abstract).

Palta, P. and M.S. Chauhan, 1998. Laboratory production of buffalo (Bubalus bubalis) embryos. Reprod. Fert. Dev., 10: 379- 391.

Plancha, C.E. and D.F. Albertini,1994. Hormonal regulation of meiotic maturation in the hamster oocyte involves a cytoskeleton-mediated process. Boil. Reprod., 51: 852- 864.

Ravindranatha, B.M., S. Nandi, P.S.P. Gupta and P.V. Sarma, 2002.In vitro effects of different levels of commercially available PMSG on oocyte maturation. Buffalo J., 1: 101- 107.

Raza, A., H.A. Samad, N.U. Rehman and E.U.H. Zia, 2001.Studies on in vitro maturation and fertilization of of Nili- Ravi buffalo follicular oocytes. Intrern. J. Agric. Biol., 3: 503- 506.

Saeki, K., M. Hoshi, M.L. Leibfried-Rutledge and N. L. First, 1990.In vitro fertilization and development of bovine oocytes matured with commercial available follicle stimulating hormone. Theriogenology, 34: 1035-1039.

Sanbuissho, A. and W.R. Threlfall, 1990.The influence of serum and gonadotropins on in vitro maturation and fertilization of bovine oocytes. Theriogenology, 34 (2): 341- 348.

Shamiah, S.M., 2004.Studies on in vitro fertilizion in Egyptian buffaloes. Ph.D. Thesis, Faculty of Agriculture, Mansoura University, Egypt.

Sirard, M.A., H.M. Florman, M.L. LeibfriedRutledge, F.L., Barnes, M.L., Sims and N.L. First, 1989.Timing of nuclear progression and protein synthesis necessary for meiotic maturation of bovine oocytes. Biol. Reprod., 40: 1257- 1263.
Smetanina, I.G, L.V. Tatarinova and A.S. Krivokharchenko, 2000.Influence of the culture medium composition on cattle oocyte maturation and embryogenesis in vitro. Russian Journal of Developmenal Biology, 31: 113-116.

Staigmiller, R.B. and R.M. Moor, 1984. Effect of follicle cells on the maturation and developmental competence of ovine oocytes matured outside the follicle. Gamete Res.,9221-229.

Totey, S.M., C.H. Pawshe and G.P. Singh, 1993.In vitro maturation and fertilization of buffalo oocytes (Bubalus bubalis), effects of media, hormones and sera. Theriogenology, 39: 1153-1171.

Totey, S.M., G. Singh, M. Taneja, C.H. Pawshe and G.P. Talwar, 1992.In vitro maturation, fertilization and development of follicular oocytes from buffalo (Bubalus bubalis). J. Reprod. Fert., 95: 597- 607.

Van De Sandt, J.J.M., A.C. Schroeder and J.J. Eppig, 1990.Culture media for mouse oocyte maturation affect subsequent embryonic development. Mol. Reprod. Develop., 25: 164- 171.

Warriach, H.M. and K.R. Chohan,2004. Thickness of cumulus cell layer is a significant factor in meiotic competence of buffalo oocytes. J. Vet. Sci., 5 (3):247- 251.

Zuelke, K.A. and B.G. Brackett, 1993. Increased glutamine metabolism in bovine cumulus cell-enclosed and denuded oocytes after in vitro maturation with Luteinizing hormone. Biol. Reprod., 48:815-820.

Zuelke, K.A. and B.G. Brackett, 1992.Effects of luteinizing hormone on glucose metabolism in cumulus -enclosed bovine oocytes matured in vitro. Biol. Reprod., 46: 267.(abstract).

Table 1. Effect of type of maturation medium on cumulus cells expansion of buffalo oocytes with different qualities

\begin{tabular}{|c|c|c|c|c|c|c|c|c|c|c|}
\hline \multirow{3}{*}{$\begin{array}{l}\text { Oocyte } \\
\text { Quality }\end{array}$} & \multirow{3}{*}{ Medium } & \multirow{3}{*}{$\mathbf{N}$} & \multicolumn{8}{|c|}{ Grade of cumulus expansion } \\
\hline & & & \multicolumn{2}{|c|}{ G0 } & \multicolumn{2}{|c|}{ G1 } & \multicolumn{2}{|c|}{ G2 } & \multicolumn{2}{|c|}{ G3 } \\
\hline & & & $\mathbf{n}$ & $\%$ & $\mathbf{N}$ & $\%$ & $\mathbf{n}$ & $\%$ & $\mathbf{n}$ & $\%$ \\
\hline \multirow{3}{*}{ Excellent } & TCM & 92 & - & - & 6 & 6.5 & 34 & 37.0 & 52 & 56.5 \\
\hline & DMEM & 86 & - & - & 15 & 17.4 & 25 & 29.1 & 46 & 53.5 \\
\hline & Mean & 178 & - & - & 21 & 11.8 & 59 & 33.2 & 98 & $55.1^{\mathrm{a}}$ \\
\hline \multirow{3}{*}{ Good } & $\mathrm{TCM}$ & 62 & 2 & 3.2 & 8 & 12.9 & 26 & 41.9 & 26 & 41.9 \\
\hline & DMEM & 107 & - & - & 23 & 21.5 & 36 & 33.6 & 48 & 44.9 \\
\hline & Mean & 169 & 2 & 1.2 & 31 & 18.3 & 62 & 36.7 & 74 & $43.8^{\mathrm{b}}$ \\
\hline \multirow{3}{*}{ Fair } & $\mathrm{TCM}$ & 72 & 12 & 16.7 & 14 & 19.4 & 36 & 50.0 & 10 & $13.9^{\mathrm{b}}$ \\
\hline & DMEM & 93 & 28 & 30.1 & 18 & 19.4 & 23 & 24.7 & 24 & $25.8^{\mathrm{a}}$ \\
\hline & Mean & 165 & 40 & 24.2 & 32 & 19.4 & 59 & 35.8 & 34 & $20.6^{\mathrm{C}}$ \\
\hline \multirow{3}{*}{ Poor } & TCM & 84 & 56 & 66.7 & 14 & 16.7 & 14 & 16.7 & - & - \\
\hline & DMEM & 86 & 66 & 76.7 & 20 & 23.3 & - & - & - & - \\
\hline & Mean & 170 & 122 & 71.8 & 34 & 20.0 & 14 & 8.2 & - & - \\
\hline
\end{tabular}

Means denoted within the same column with different superscripts are significantly different at $\mathrm{P}<0.05$. N: Total number of oocytes. Grade 0 (Go): no expansion, Grade 1 (G1): few expansions of cumulus layers, Grade 2 (G2): moderate expansions of cumulus layers and Grade $3(\mathrm{G} 3)$ : full expansion of cumulus layers. 
Table 2. Effect of type of maturation medium (TCM-199 vs. DMEM) on in vitro maturation rate of buffalo oocytes with different qualities

\begin{tabular}{|c|c|c|c|c|c|c|c|c|c|c|c|c|c|c|}
\hline \multirow{3}{*}{ Medium } & \multirow{3}{*}{$\mathbf{N}$} & \multicolumn{4}{|c|}{ Immature oocytes } & \multicolumn{6}{|c|}{ Mature oocytes } & \multirow{2}{*}{\multicolumn{2}{|c|}{$\begin{array}{l}\text { Degen. } \\
\text { oocytes }\end{array}$}} & \multirow{3}{*}{$\begin{array}{l}\text { MR } \\
(\%)\end{array}$} \\
\hline & & \multicolumn{2}{|c|}{ GV } & \multicolumn{2}{|c|}{ GVBD } & \multicolumn{2}{|c|}{ Anaphase } & \multicolumn{2}{|c|}{ Telophase } & \multicolumn{2}{|c|}{ M II } & & & \\
\hline & & $\mathbf{n}$ & $\%$ & $\mathbf{n}$ & $\%$ & $\mathbf{n}$ & $\%$ & $\mathbf{N}$ & $\%$ & $\mathbf{n}$ & $\%$ & $\mathbf{n}$ & $\%$ & \\
\hline \multicolumn{15}{|c|}{ Excellent oocytes: } \\
\hline TCM & 65 & - & - & 16 & 24.6 & 12 & 18.5 & 8 & 12.3 & 27 & 41.5 & 2 & 3.1 & 72.3 \\
\hline DMEM & 64 & - & - & 12 & 18.8 & 12 & 18.8 & 9 & 14.1 & 31 & 48.4 & - & - & 81.3 \\
\hline Mean & 129 & - & - & 28 & 21.7 & 24 & 18.6 & 17 & 13.2 & 58 & 45.0 & 2 & 1.6 & $76.7^{\mathrm{a}}$ \\
\hline \multicolumn{15}{|c|}{ Good oocytes: } \\
\hline TCM & 45 & - & - & 7 & 15.6 & 9 & 20.0 & 6 & 13.3 & 14 & 31.1 & 9 & 20.0 & 64.4 \\
\hline DMEM & 82 & - & - & 12 & 14.6 & 21 & 25.6 & 9 & 11.0 & 31 & 37.8 & 9 & 11.0 & 74.4 \\
\hline Mean & 127 & - & - & 19 & 15.0 & 30 & 23.6 & 15 & 11.8 & 45 & 35.4 & 18 & 14.2 & $70.9^{\mathrm{a}}$ \\
\hline \multicolumn{15}{|c|}{ Fair oocytes: } \\
\hline $\mathrm{TCM}$ & 56 & 10 & 17.86 & 23 & 41.1 & 1 & 1.8 & 1 & 1.8 & 13 & 23.2 & 8 & 14.3 & $26.8^{\mathrm{b}}$ \\
\hline DMEM & 66 & 5 & 7.58 & 18 & 27.3 & 10 & 15.2 & 8 & 12.1 & 16 & 24.2 & 9 & 13.6 & $51.5^{\mathrm{a}}$ \\
\hline Mean & 122 & 15 & 12.30 & 41 & 33.6 & 11 & 9.0 & 9 & 7.4 & 29 & 23.8 & 17 & 13.9 & $40.2^{\mathrm{b}}$ \\
\hline \multicolumn{15}{|c|}{ Poor oocytes: } \\
\hline $\mathrm{TCM}$ & 56 & 14 & 25.00 & 18 & 32.1 & - & - & 1 & 1.8 & 8 & 14.3 & 15 & 26.8 & $16.1^{b}$ \\
\hline DMEM & 58 & 7 & 12.07 & 13 & 22.4 & 13 & 22.4 & 2 & 3.5 & 4 & 6.9 & 19 & 32.8 & $32.8^{\mathrm{a}}$ \\
\hline Mean & 114 & 21 & 18.42 & 31 & 27.2 & 13 & 11.4 & 3 & 2.6 & 12 & 10.5 & 34 & 29.8 & $24.6^{\mathrm{c}}$ \\
\hline
\end{tabular}

Table 3. Effect of hormonal addition to maturation medium (TCM-199 or DMEM) on cumulus cells expansion of buffalo oocytes with different qualities

\begin{tabular}{|c|c|c|c|c|c|c|c|c|c|c|}
\hline \multirow{3}{*}{ Hormone } & \multirow{3}{*}{ Medium } & \multirow{3}{*}{$\mathbf{N}$} & \multicolumn{8}{|c|}{ Grade of cumulus expansion } \\
\hline & & & \multicolumn{2}{|c|}{ G0 } & \multicolumn{2}{|c|}{ G1 } & \multicolumn{2}{|c|}{ G2 } & \multicolumn{2}{|c|}{ G3 } \\
\hline & & & $\mathbf{n}$ & $\%$ & $\mathbf{n}$ & $\%$ & $\mathbf{n}$ & $\%$ & $\mathbf{n}$ & $\%$ \\
\hline \multicolumn{11}{|c|}{ Excellent oocytes } \\
\hline \multirow{2}{*}{ FSH } & TCM & 27 & - & - & 3 & 11.1 & 11 & 40.7 & 13 & $48.2^{c}$ \\
\hline & DMEM & 29 & - & - & - & - & 6 & 20.7 & 23 & $79.3^{\mathrm{a}}$ \\
\hline \multirow{2}{*}{$\mathrm{FSH}+\mathrm{hCG}$} & TCM & 65 & - & - & 3 & 4.6 & 23 & 35.4 & 39 & $60.0^{\mathrm{b}}$ \\
\hline & DMEM & 57 & - & - & 15 & 26.3 & 19 & 33.3 & 23 & $40.4^{\mathrm{c}}$ \\
\hline \multicolumn{11}{|c|}{ Good oocytes } \\
\hline \multirow{2}{*}{ FSH } & TCM & 20 & - & - & 4 & 20.0 & 8 & 40.0 & 8 & $40.0^{\mathrm{b}}$ \\
\hline & DMEM & 37 & - & - & 4 & 10.8 & 8 & 21.6 & 25 & $67.6^{\mathrm{a}}$ \\
\hline \multirow{2}{*}{ FSH+hCG } & TCM & 42 & 2 & 4.8 & 4 & 9.5 & 18 & 42.9 & 18 & $42.9^{b}$ \\
\hline & DMEM & 70 & - & - & 19 & 27.1 & 28 & 40.0 & 23 & $32.9^{\mathrm{bc}}$ \\
\hline \multicolumn{11}{|c|}{ Fair oocytes } \\
\hline \multirow{2}{*}{ FSH } & TCM & 25 & 2 & 8.0 & 8 & 32.0 & 11 & 44.0 & 4 & $16.0^{\mathrm{b}}$ \\
\hline & DMEM & 36 & - & - & 2 & 5.6 & 16 & 44.4 & 18 & $50.0^{\mathrm{a}}$ \\
\hline \multirow{2}{*}{ FSH+hCG } & TCM & 47 & 10 & 21.3 & 6 & 12.8 & 25 & 53.2 & 6 & $12.8^{\mathrm{b}}$ \\
\hline & DMEM & 57 & 28 & 49.1 & 16 & 28.1 & 7 & 12.3 & 6 & $10.5^{\mathrm{b}}$ \\
\hline \multicolumn{11}{|c|}{ Poor oocytes } \\
\hline \multirow{2}{*}{ FSH } & TCM & 21 & 15 & 71.4 & 2 & 9.5 & 4 & 19.1 & - & - \\
\hline & DMEM & 40 & 20 & 50.0 & 20 & 50.0 & - & - & - & - \\
\hline \multirow{2}{*}{ FSH+hCG } & TCM & 63 & 41 & 65.1 & 12 & 19.1 & 10 & 15.9 & - & - \\
\hline & DMEM & 46 & 100 & - & - & - & - & - & - & - \\
\hline
\end{tabular}

Means denoted within the same column for each oocyte quality with different superscripts are significantly different at $\mathrm{P}<0.05$. N: total number of oocytes, Grade 0 (Go): no expansion, Grade 1 (G1): few expansions of cumulus layers, Grade 2 (G2): moderate expansions of cumulus layers and Grade 3 (G3): full expansion of cumulus layers. 
Table 4. Effect of hormonal addition to maturation medium (TCM-199 or DMEM) on maturation rate of buffalo oocytes with different qualities

\begin{tabular}{|c|c|c|c|c|c|c|c|c|c|c|c|c|c|c|c|}
\hline \multirow{3}{*}{ Hormone } & \multirow{3}{*}{ Med. } & \multirow{3}{*}{$\mathbf{N}$} & \multicolumn{4}{|c|}{ Immature oocytes } & \multicolumn{6}{|c|}{ Mature oocytes } & \multirow{2}{*}{\multicolumn{2}{|c|}{$\begin{array}{l}\text { Degen. } \\
\text { Oocyte }\end{array}$}} & \multirow{3}{*}{$\begin{array}{l}\text { MR } \\
(\%)\end{array}$} \\
\hline & & & \multicolumn{2}{|c|}{ GV } & \multicolumn{2}{|c|}{ GVBD } & \multicolumn{2}{|c|}{ Anaph. } & \multicolumn{2}{|c|}{ Teloph. } & \multicolumn{2}{|c|}{ M II } & & & \\
\hline & & & $\mathbf{N}$ & $\%$ & $\mathbf{n}$ & $\%$ & $\mathbf{n}$ & $\%$ & $\mathbf{n}$ & $\%$ & $\mathbf{n}$ & $\%$ & $\mathbf{n}$ & $\%$ & \\
\hline \multicolumn{16}{|c|}{ Excellent oocytes: } \\
\hline \multirow{2}{*}{ FSH } & TCM & 24 & - & - & 6 & 25.0 & 5 & 20.8 & 3 & 12.5 & 9 & 37.5 & 1 & 4.17 & $70.8^{\mathrm{b}}$ \\
\hline & DMEM & 24 & - & - & 5 & 20.8 & 4 & 16.7 & 4 & 16.7 & 11 & 45.8 & - & - & $79.2^{\mathrm{ab}}$ \\
\hline \multirow{2}{*}{$\begin{array}{c}\mathrm{FSH}+ \\
\mathrm{hCG}\end{array}$} & TCM & 41 & - & - & 10 & 24.4 & 7 & 17.1 & 5 & 12.2 & 18 & 43.9 & 1 & 2.44 & $73.2^{\mathrm{b}}$ \\
\hline & DMEM & 40 & - & - & 7 & 17.5 & 8 & 20.0 & 5 & 12.5 & 20 & 50.0 & - & - & $82.5^{\mathrm{a}}$ \\
\hline \multicolumn{16}{|c|}{ Good oocytes: } \\
\hline \multirow{2}{*}{ FSH } & TCM & 18 & - & - & 4 & 22.2 & 4 & 22.2 & 2 & 11.1 & 5 & 27.8 & 3 & 16.67 & $61.1^{\mathrm{b}}$ \\
\hline & DMEM & 31 & - & - & 5 & 16.1 & 8 & 25.8 & 3 & 9.7 & 11 & 35.5 & 4 & 12.90 & $71.0^{\mathrm{ab}}$ \\
\hline \multirow{2}{*}{$\mathrm{FSH}+\mathrm{hCG}$} & TCM & 27 & - & - & 3 & 11.1 & 5 & 18.5 & 4 & 14.8 & 9 & 33.3 & 6 & 22.22 & $66.7^{\mathrm{b}}$ \\
\hline & DMEM & 51 & - & - & 7 & 13.7 & 13 & 25.5 & 6 & 11.8 & 20 & 39.2 & 5 & 9.80 & $76.5^{\mathrm{a}}$ \\
\hline \multicolumn{16}{|c|}{ Fair oocytes: } \\
\hline \multirow{2}{*}{$\mathrm{FSH}$} & TCM & 24 & 4 & 16.7 & 11 & 45.8 & 1 & 4.2 & - & - & 5 & 20.8 & 3 & 12.50 & $25.0^{\mathrm{b}}$ \\
\hline & DMEM & 28 & 3 & 10.7 & 6 & 21.4 & 4 & 14.3 & 3 & 10.7 & 7 & 25.0 & 5 & 17.86 & $50.0^{\mathrm{a}}$ \\
\hline \multirow{2}{*}{$\begin{array}{l}\text { FSH+ } \\
\text { hCG }\end{array}$} & TCM & 32 & 6 & 18.8 & 12 & 37.5 & - & - & 1 & 3.1 & 8 & 25.0 & 5 & 15.63 & $28.1^{\mathrm{b}}$ \\
\hline & DMEM & 38 & 2 & 5.3 & 12 & 31.6 & 6 & 15.8 & 5 & 13.2 & 9 & 23.7 & 4 & 10.53 & $52.6^{\mathrm{a}}$ \\
\hline \multicolumn{16}{|c|}{ Poor oocytes: } \\
\hline \multirow{2}{*}{ FSH } & TCM & 20 & 5 & 25.00 & 6 & 30.0 & - & - & 1 & 5.00 & 2 & 10.00 & 6 & 30.00 & $15.0^{\mathrm{c}}$ \\
\hline & DMEM & 29 & 3 & 10.34 & 7 & 24.1 & 7 & 24.14 & - & - & 4 & 13.79 & 8 & 27.59 & $37.9^{\mathrm{a}}$ \\
\hline \multirow{2}{*}{$\begin{array}{c}\text { FSH+ } \\
\text { hCG }\end{array}$} & TCM & 36 & 9 & 25.00 & 12 & 33.3 & - & - & - & - & 6 & 16.67 & 9 & 25.00 & $16.7^{\mathrm{c}}$ \\
\hline & DMEM & 29 & 4 & 13.79 & 6 & 20.7 & 6 & 20.69 & 2 & 6.90 & - & - & 11 & 37.93 & $27.6^{\mathrm{b}}$ \\
\hline
\end{tabular}

تاثير بيئات الإنضاج مع الإضافة الهرمونية على إنضاج بويضات الجاموس مختلفة الجودة معلياً

شريف عبد الونيس جبر

قسم الاتتاج الحيوانى، كلية الزراعة، جامعة طنطا

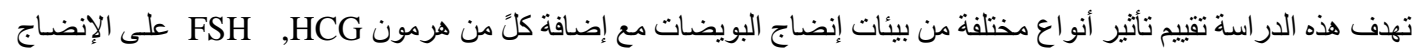

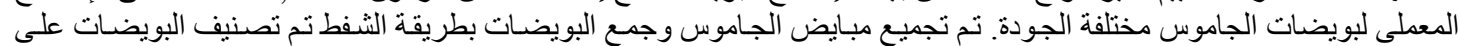

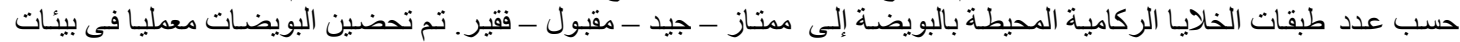
معSH لدع TCM.199 ， DMEM

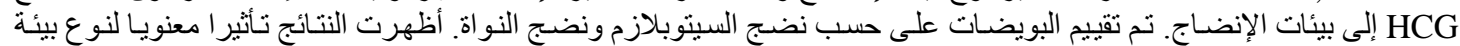

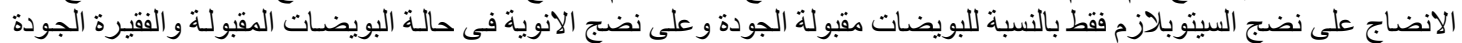

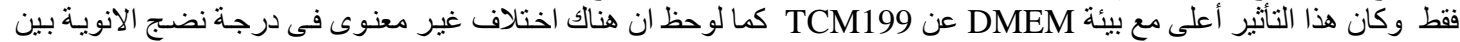

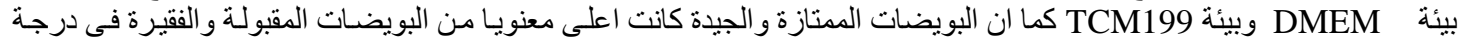

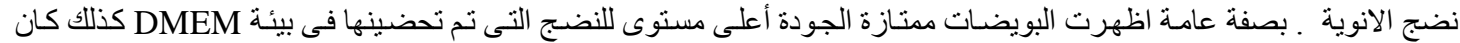

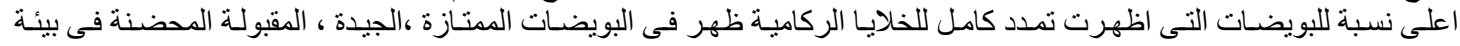

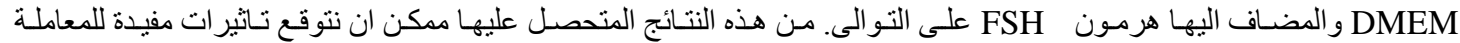

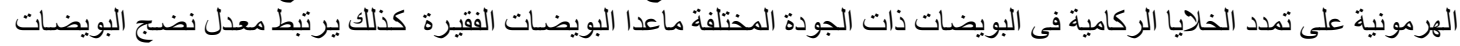

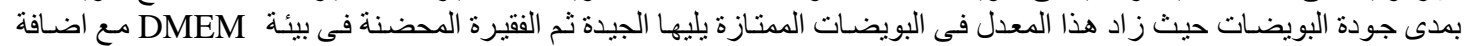

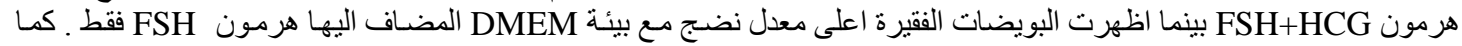

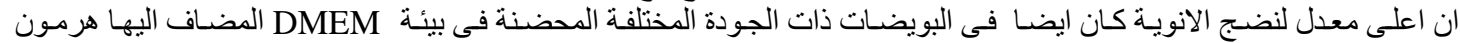
. FSH+HCG المعملى والتطور الجنينى لبويضات الجاموس. 